\title{
INVESTIGATION ON THE USE OF AMERICIUM OXIDE FOR SPACE POWER SOURCES: RADIATION DAMAGE STUDIES
}

\author{
T. Wiss $^{(1)}$, D. Freis ${ }^{(1)}$, J.-C. Griveau ${ }^{(1)}$, K. Popa ${ }^{(1)}$, J.-F. Vigier $^{(1)}$, J. Somers ${ }^{(1)}$, E. D'Agata $^{(2)}$, R.J.M. Konings ${ }^{(1)}$, O. \\ Benes $^{(1)}$, J.-Y. Colle ${ }^{(1)}$, O. Dieste ${ }^{(1)}$ \\ ${ }^{(1)}$ European Commission, Joint Research Centre, Directorate G-Nuclear Safety \& Security, P.O. box 2340, 76125 \\ Karlsruhe, Germany, Email:thierry.wiss@ec.europa.eu \\ (2) European Commission, Joint Research Centre, Directorate G-Nuclear Safety \& Security, P.O. Box 2, NL-1755 ZG \\ Petten, The Netherlands, Email:elio.dagata@ec.europa.eu
}

\begin{abstract}
Within Europe ${ }^{241} \mathrm{Am}$ is a feasible alternative to ${ }^{238} \mathrm{Pu}$ that can provide a heat source for radioisotope thermoelectric generators (RTGs) and radioisotope heating units (RHUs) to be used in Electrical power sources used in outer planet missions. In the EPSOSPACE* project developed as an exploratory research at JRC, a new type of nuclear power source, to provide heat and electricity for deep space missions is considered. It will consist of a ${ }^{241} \mathrm{Am}$ based compound with aerogel thermal insulation and thermocouples in close contact with the heat source. The assembly is inside an iridium encapsulation to withstand all relevant accident scenarios. The design will be modular and combinable for required electrical output.

Several candidate Americium compounds will be investigated for chemical stability at high temperature and for self-irradiation damage. New thermo-electric converter materials containing actinides will be assessed, and a robust encapsulation designed. Safety analyses will be performed including launch explosion and re-entry accidents. The research will conclude in a conceptual design of a prototype power source. In the first part of this study, americium dioxide will be considered from the point of view of its chemical durability and of its behavior against radiation damage and helium formation, two aspects to be carefully investigated due to the high alpha-activity of the americium. Transmission electron Microscopy (TEM) and helium thermal desorption spectrometry (TDS) experiments will be described and results on aged (more than 30 years) $\mathrm{AmO}_{2}$ reported. Some comparison with ${ }^{238} \mathrm{PuO}_{2}$ based RTG's will be discussed.
\end{abstract}

\section{INTRODUCTION}

In the space conquest century, several satellites are to be sent to the outer space. In order to keep instruments running over several decades, with no direct physical contact to Earth, these space crafts need long-time batteries $[1,2] .{ }^{238} \mathrm{Pu}$ has been the isotope of choice for five decades. O'Brien et al. [3] have made an detailed review on the different radioisotopes to be used in as alternatives to ${ }^{238} \mathrm{Pu}$ that is traditionally used in radioisotope thermoelectric generators and heating units. The main problem of ${ }^{238} \mathrm{Pu}$ is the availability and price. In addition, having a half-life of $87.5 \mathrm{y}$, after several years of operation, the power of the plutoniumbased batteries diminishes. Hence, the electronics need to be far more complicated than usual.

As alternative, it has been proposed to use ${ }^{241} \mathrm{Am}$. To its credit, the reserves of this actinide at the moment are large, and more can be produced.

One possibility of obtaining ${ }^{241} \mathrm{Am}$ is by reprocessing spent fuel, which contains about $12 \%{ }^{241} \mathrm{Pu}$. (from the total $\mathrm{Pu}$ inventory at discharge). Because it spontaneously converts to ${ }^{241} \mathrm{Am},{ }^{241} \mathrm{Pu}$ can be extracted and may be used to generate further ${ }^{241} \mathrm{Am}$. However, this process is slow: Half of the original amount of ${ }^{241} \mathrm{Pu}$ decays to ${ }^{241} \mathrm{Am}$ in about 15 years, and the ${ }^{241} \mathrm{Am}$ amount reaches a maximum after $70 \mathrm{y}$.

As ${ }^{241} \mathrm{Am}$ has a significantly longer half-life than ${ }^{238} \mathrm{Pu}$ $(432 y$ vs. $87 y)$, the power of the batteries would be much more stable, simplifying the design of the electronics. As withdraw, the peak-power would be lower $(114.7 \mathrm{~mW} / \mathrm{g}$ vs. $390 \mathrm{~mW} / \mathrm{g})$, and the weight needed much higher than usual batteries, but the lower price on the precursor material makes it more suitable.

To be able to design suitable space batteries, more studies on ${ }^{241} \mathrm{AmO}_{2}$ need to be made. To this matter, a comparison between its microstructure evolution to the one of ${ }^{238} \mathrm{PuO}_{2}$ can be of use.

The chemical and physical consequences of selfradiation in actinide compounds are rather complex. It is often difficult to deduce the true physicochemical properties of substances when superimposed by radioactive decays and their effects.

Alpha-decays in oxides typically results in the formation of points defects, mainly from the recoil nucleus and to the formation of a helium atom when the alpha-particle comes to rest. The point defects can also precipitate into larger extended defects (e.g. dislocation loops) and the helium atoms into bubbles. To observe these types of microstructural features the ideal probe is a Transmission Electron Microscope that enables with modern instrument to easily visualize objects in the nanometer (even lower) scale. In addition to conventional imaging, elemental (EDX) and spectroscopic analyses (EELS) proved to be of additional help to characterize the change in 
microstructure due to alpha-decay damage [4].

An effect of self-radiation and radioactive decay is the change in impurity content of the compound, due to the ingrowing daughter(s). This change influences the electrical resistivity as well as the lattice parameters. Other effects, which can be regarded as primary effects of the decay process are: the ionization, electronic excitation and atomic displacements. The relative magnitude of each of these phenomena depends on the type and energy of the particle and on the substances.

To our Knowledge, the effect of ${ }^{241} \mathrm{Am}$ self-irradiation has been previously studied for $\mathrm{AmO}_{2}$, however, the majority of the work conducted has been limited to the effect of self-irradiation on the lattice parameter $[5,6]$ and thermal conductivity [7]. Much more work was performed on ${ }^{238} \mathrm{PuO}_{2}$ since this compounds has already been used in RTG's including batteries for space probes and even in pacemakers $[8,9]$.

\section{EXPERIMENTAL}

The original ${ }^{238} \mathrm{PuO}_{2}$ from a ${ }^{242} \mathrm{Cm}$ RTG fabricated in 1968 with $450 \mathrm{mg}$ of ${ }^{242} \mathrm{Cm}$-oxyde powder delivering a total thermal power of 45 Watts was retrieved. The curium from the RTG was isolated from additional americium and cerium content by successive selective dissolution of the actinides and precipitation of an oxidized-americium carbonate. After 4.5 half-lives $\left(\mathrm{T}_{1 / 2}\right.$ $=162 \mathrm{~d})$ the ${ }^{238} \mathrm{Pu}$ was isolated and converted into an oxalate before being calcined into an oxide powder. The isotopic analysis has revealed enrichment by $98.936 \%$ of the isotope-238.

Two $\mathrm{AmO}_{2}$ samples were retrieved from the JRC - ITU archives after several years of storage [10]. No particular precautions regarding the storage were takensamples were stored in air and at room temperature.

The investigations have been performed on a FEI Tecnai $\mathrm{G}^{2}$ TEM, equipped with a GATAN Tridiem GIF camera, an EDAX energy dispersive X-ray analysis system, a tomography suite and a HAADF (High-Angle Annular Dark Field) detector for the STEM (Scanning Transmission Electron Microscopy) imaging. The TEM has been adapted for the examination of highly active or irradiated nuclear materials thanks to a flange that has been inserted in the octagon hosting the objective lenses, and a glove box mounted on this flange around the compustage [11]. Thus, the sample can be moved from the glove box where it was prepared to the microscope making use of a La Calhène DPTE ${ }^{\circledR}$ system.

\section{TEM INVESTIGATION}

Fig. 1 shows a bright field transmission electron microscope (TEM) image of a sample of $\mathrm{AmO}_{2}$ having cumulated a dose of $1.4 \times 10^{20} \alpha \cdot \mathrm{g}^{-1}$ after 36 years of storage. A population of very small intragranular nanometer sized bubbles was observed. In this area the bubbles are homogeneously distributed and their concentration amounts around $5 \times 10^{22} \mathrm{~m}^{-3}$. In some other areas as reported in [4] some larger bubbles of several nanometers were founds but with a rather low concentration. Very few extended defects were found even at the damage level of $36 \mathrm{dpa}$ which highlights an excellent resistance to alpha-damage build-up as also shown in [10].

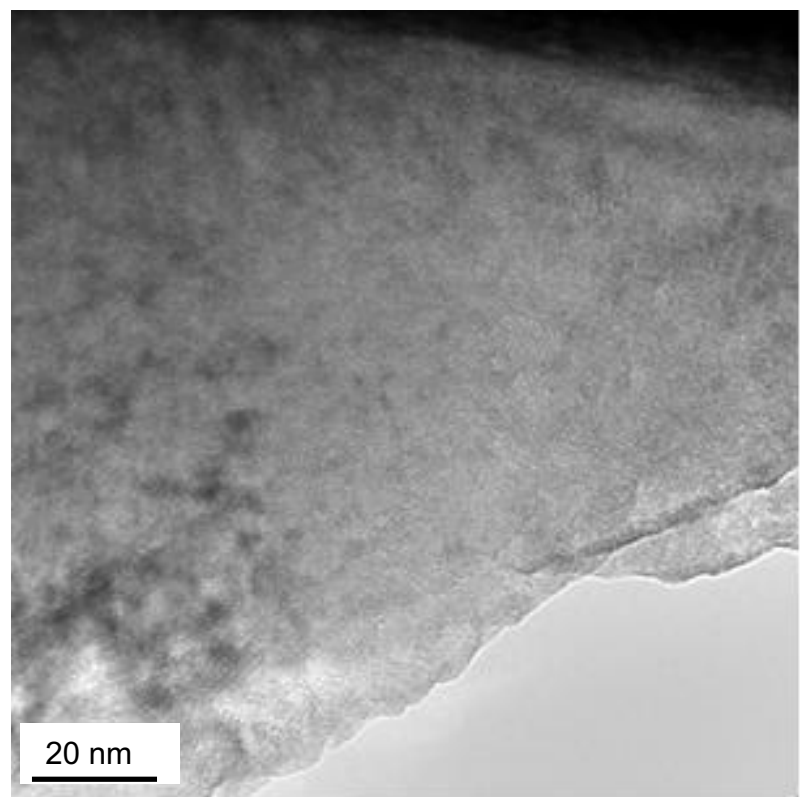

Figure 1. TEM bright field image of ${ }^{241} \mathrm{AmO}_{2}$ after cumulating $1.4 \times 10^{20} \alpha \cdot g^{-1}$ and showing a high concentration of $\sim 5 \times 10^{22} \mathrm{~m}^{-3}$ sub-nanometric helium bubbles (tinny white spots).

The microstructure of the ${ }^{238} \mathrm{PuO}_{2}$ has also been investigate as shown in the TEM bright field micrograph of Fig. 2. Helium bubbles of less than a nanometer were observed. Their concentration was measured to be $5 \times 10^{23} \mathrm{~m}^{-3}$ hence one order of magnitude higher than for the ${ }^{241} \mathrm{AmO}_{2}$ sample for a cumulated dose 3 times higher than in the later sample. However, the size at this resolution is extremely difficult to assess very precisely and in addition to an increase in concentration it needs to e considered that also the size increases with helium formation. The AmO2 samples have also shown larger bubbles and even if not at a high concentration potentially containing a non-negligible part of the total inventory. More work needs to be performed to assess the retained fraction of helium by thermal desorption spectrometry as performed in the ${ }^{238} \mathrm{PuO}_{2}$ sample for example [12]. 


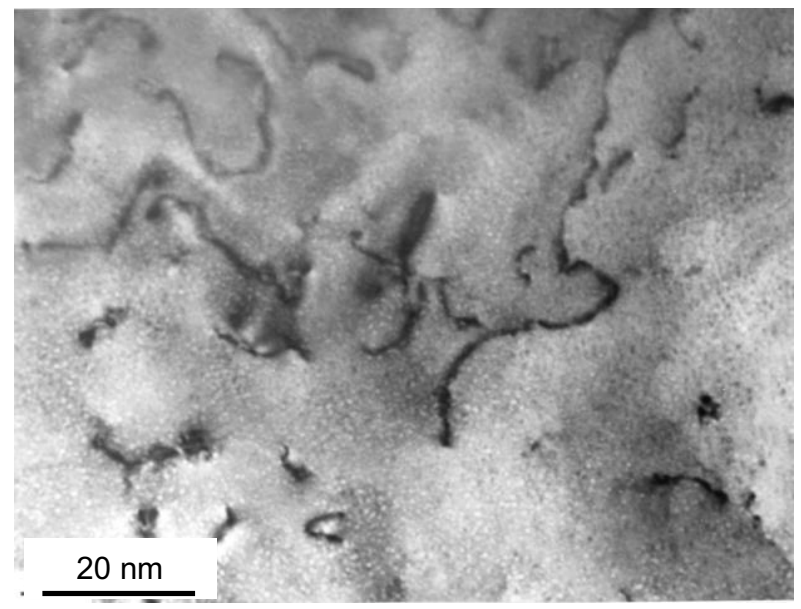

Figure 2. TEM bright field image of ${ }^{238} \mathrm{PuO}_{2}$ after cumulating $3.67 \times 10^{20} \alpha \cdot g^{-1}$ and showing a high concentration of $\sim 5 \times 10^{23} \mathrm{~m}^{-3}$ nanometric helium bubbles.

\section{XRD ANALYSES}

In the actinide oxides there is a homogeneous distribution of alpha-damage leading to a rapid saturation of the lattice parameter [13-15]. The graph in Fig. 3 shows that the saturation of the lattice parameter for the lattice parameter for the ${ }^{238} \mathrm{PuO}_{2}$ and the ${ }^{241} \mathrm{AmO}_{2}$ is just below $0.3 \%$. The self-radiation effects on the lattice parameter of $\mathrm{PuO}_{\mathrm{x}}$ have been studied on ${ }^{238} \mathrm{PuO}_{\mathrm{x}}$ samples $[13,16]$. Lattice parameter increase was determined for samples stored at ambient temperature in oxygen or in vacuum, for samples stored at liquid nitrogen temperature and for samples containing $5 \% \mathrm{Fe}$ (III) and kept under pure oxygen at room temperature.

The ingrowth of damage is frequently described by a simple exponential function. The lattice parameter change $\Delta \mathrm{a} / \mathrm{a}_{0}$ can be described [16] by:

$$
\Delta \mathrm{a} / \mathrm{a}_{0}=\mathrm{A}\left(1-\mathrm{e}^{-\mathrm{B} \lambda \mathrm{t}}\right)
$$

Where

$\lambda$ : decay constant

t: time

A: value at saturation

B: rate constant for simultaneous annealing of defects.

The value A can be influenced by the history of the specimen used $[15,17]$. The effects due to atomic displacements are rather complex functions describing the relative sink strengths of a given specimen for interstitial and vacancies. The formation of extended defects like dislocation loops [18] or of helium bubbles $[19,20]$ can provide additional sinks. Local maximum and minimum values observed for the lattice parameter as a function of accumulated damage before reaching a saturation level have been attributed to the trapping of interstitials into (helium) sinks. At saturation, the recombination rate is equal to the production rate of Frenkel defects. In the experiments of Chikalla and Turcotte [14] saturation is observed for lattice expansion of $\sim 0.3 \%$. This value is in substantial agreement with the measurements of Noe and Fuger [13] in various systems where a lattice expansion at saturation of $0.28 \%$ was measured.

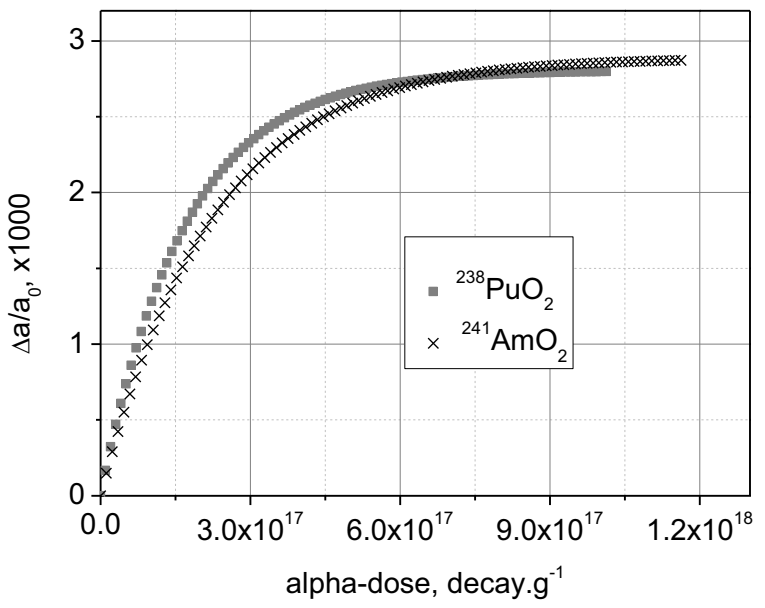

Figure 3. relative lattice parameter evolution as function of accumulated alpha-damage ${ }^{241} \mathrm{AmO}_{2}$ stored in vacuum from ref. [5] and ${ }^{238} \mathrm{PuO}_{2}$ stored in vacuum from ref.[14] respectively.

It is therefore to be expected that a lattice swelling of about $2 \%$ can be reach at saturation, hence after 100 days for the ${ }^{241} \mathrm{AmO}_{2}$ and after less than a month for the ${ }^{238} \mathrm{PuO}_{2}$.

Larger swelling, however, has to be accounted for due to the radiogenic helium formation. From the helium bubble distribution in the ${ }^{238} \mathrm{PuO}_{2}$ sample analysed by TEM it was calculated that a volumetric swelling of $3 \%$ could be reached [12].

\section{CONCLUSION}

Despite the high $\alpha$-irradiation dose in $\mathrm{AmO}_{2}$, the samples studied remained crystalline. The microstructure examination of this material revealed that only few extended defects are formed. Given the very high alpha-dose the material has experienced it is indicating a rather good resistance to radiation damage build-up. On the other side there is a background of subnanometric bubbles that can be observed in this material. The lattice parameter evolution shows saturation at a value of $0.28 \%$ but the formation of bubbles at very large cumulated dose should be accounted for when determining the total swelling of such compounds. Such parameters are of importance when designing batteries envelops for example. In 
comparison with ${ }^{238} \mathrm{PuO}_{2}$ which was substantially more studied, ${ }^{241} \mathrm{AmO}_{2}$ shows a good behaviour against damage build-up which makes it a good candidate for RTG's from this perspective. Work is in progress to determine the helium behaviour in the $\mathrm{AmO}_{2}$ and especially to determine the helium retention capacity this fluorite type material. The design and particularly the porosity should account for such parameters.

\section{REFERENCES}

1. Prelas, M. Weaver, C. Watermann, M. Lukosi, E. Schott, R., Wisniewski, D. (2014). A review of nuclear batteries. Progress in Nuclear Energy. 75, 117-149.

2. Lange, R., Carroll, W. (2008). Review of recent advances of radioisotope power to explore the solar system, Energy Conv. Manag. 43(3), 393401.

3. O'Brien, R.C. Ambrosi, R.M. Bannister, N.P. Howe, S.D. and Atkinson, H.V. (2008). Safe radioisotope thermoelectric generators and heat sources for space applications. J. Nucl. Mater. 377, 506-521.

4. Wiss, T., Dieste Blanco, O., Tacu, A., Janssen, A., Talip, Z., Colle, J. Y., Martin, P., Konings, R. J. M. (2015). TEM Study of Alpha-damaged Plutonium and Americium Dioxides. J. Mater. Res. 30, 1544-1554.

5. Hurtgen, C., Fuger, J. (1977), Self-irradiation Effects in Americium Oxides, Inorg. Nucl. Chem. Lett. 13, 179-188

6. Nellis, W.J. (1977). The Effect of Self-Radiation on Crystal Volume, Inorganic and Nuclear Chemistry Letters 13, 393-398.

7. Schmidt, H.E., Richter, J., Matzke, H., Van Geel, J., (1994). The Effect of Self-Irradiation on the Thermal Conductivity of Plutonium and Americium Oxides, in: T.W. Tong (Ed.) Thermal Conductivity 22, Technoic Publ. Co., Lancaster, PA, 920-925.

8. Boucher, R., Quéré, Y. (1981). Sources d'énergie au plutonium pour stimulateurs cardiaques, J. Nucl. Mater. 100, 132-136.

9. Alais, M., Berger, R., Boucher, R., Gasper, K.A., Laurens, P. (1974). Nucl. Tech. 26, 307-319.

10. Prieur, D. Vigier, J.-F. Wiss, T. Janssen, A. Rothe,
J. Cambriani, A. Somers. (2014). J. Structural investigation of self-irradiation damaged $\mathrm{AmO}_{2}$, Journal of Solid State Chemistry 212, 7-12.

11. Wiss, T., Thiele, H., Janssen, A., Papaioannou, D., Rondinella, V.V., Konings. R.J.M. (2013). Recent results of Microstructural Characterization of Irradiated Light Water Reactor Fuels using Scanning and Transmission Electron Microscopy, JOM 64, 1390-1395

12. Wiss, T., Hiernaut, J. P., Roudil, D., Colle, J. Y., Maugeri, E., Talip, Z.,Janssen, A., Rondinella, V. V., Konings, R. J. M., Matzke, H., Weber, W. (2014) Evolution of spent fuel in dry storage conditions for millennia and beyond. J. Nucl. Mater. 451, 198-206.

13. Noe, M. Fuger, J. (1974). Self-radiation effects on the lattice parameter of ${ }^{238} \mathrm{PuO}_{2}$, Inorganic and Nuclear Chemistry Letters 10, 7-19.

14. Chikalla, T. D., Turcotte, R. P. (1973). Radiation Effects 19, 93-98.

15. Fuger, J. Matzke, H. (1991). Handbook on the Physics and Chemistry of the Actinides (eds. Freeman, A. J. \& Keller, C.), Elsevier Science Publishers B.V., 641 -684.

16. Weber, W. (1984). Alpha-irradiation damage in $\mathrm{CeO}_{2}$ and $\mathrm{PuO}_{2}$. Radiation Effects 83, 145-156.

17. Turcotte, R., Chikalla, T. (1973). Annealing of self-radiation damage in ${ }^{238} \mathrm{PuO}_{2}$, Radiation Effects 19, 99-108.

18. Jonnet, J. Van Uffelen, P., Wiss, T., Staicu, D., Rémy, B., Rest, J. (2008). Growth mechanisms of interstitial loops in $\alpha$-doped $\mathrm{UO}_{2}$ samples, Nuclear Instruments and Methods in Physics Research, Section B: Beam Interactions with Materials and Atoms. 266(12-13), 3008-3012.

19. Maugeri, E., Wiss, T., Hiernaut, J. P., Desai, K., Thiriet, C., Rondinella, V. V., Colle, J. Y., Konings, R. J. M. (2009). Helium solubility and behaviour in uranium dioxide. J. Nucl. Mater. 385, 461-466.

20. Rondinella, V. V., Wiss, T., Matzke, H., Hiernaut, J. P., Fromknecht, R. (2000). in Mass and Charge Transport in Inorganic Materials, Adv. in Science and Technology 499-506. 